\title{
Advances in Environmental and Engineering Research
}

Short communication

\section{Impact of Covid-19 Pandemic on Air Transport: Overview and Implications}

Maurizio Arena ${ }^{1,{ }^{*},+}$, Claudia Aprea ${ }^{2,+}$

1. Department of Industrial Engineering, Università degli Studi di Napoli "Federico II", via Claudio 21, 80125, Napoli, Italy; E-Mail: maurizio.arena@unina.it

2. Department of Humanities, Università degli Studi di Napoli "Federico II", via Porta di Massa 1, 80133, Napoli, Italy; E-Mail: clau.aprea@studenti.unina.it

+ These authors contributed equally to this work.

* Correspondence: Maurizio Arena; E-Mail: maurizio.arena@unina.it

Academic Editor: Zed Rengel

Adv Environ Eng Res

2021, volume 2, issue 1

doi:10.21926/aeer.2101002
Received: December 16, 2020

Accepted: February 15, 2021

Published: February 22, 2021

\begin{abstract}
The current situation of the COVID-19 pandemic has led to multiple changes in the international market as well as in the lifestyle of people worldwide. The transport sector has undoubtedly been one of the most affected sectors due to restrictions imposed by the governments across the world to protect the health of their citizens, particularly the restrictions imposed on the operation of airlines. On the other hand, the reduction in travel by means of transport has contributed in part to the improvement in the environmental conditions on account of reduction in the levels of $\mathrm{CO}_{2}$ emissions and pollution. The present paper discusses the major consequences of the COVID-19 pandemic on the aviation industry. The data and critical observations presented in this paper were collected from the detailed studies published on this crucial topic and thus provide a broad overview to the reader.
\end{abstract}

\section{Keywords}

Air transport; COVID-19; economy; health; pollution

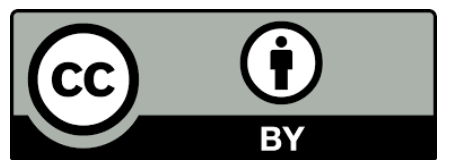

(C) 2021 by the author. This is an open access article distributed under the conditions of the Creative Commons by Attribution License, which permits unrestricted use, distribution, and reproduction in any medium or format, provided the original work is correctly cited. 


\section{Introduction}

\subsection{Pandemic Aspects}

The COVID-19 pandemic outbreak of 2019-2020, which is currently continuing, has suddenly disturbed the daily lives of billions of people across the world. The first confirmed cases were reported between the months of November and December in the year 2019 and concerned a few workers in the wet market of Wuhan, in the province of Hubei, China, which is a really important political, economic, financial, cultural, and educational center of China. The infected patients exhibited the symptoms of a strange kind of pneumonia, which immediately became the subject of study and research among the Chinese scholars, who identified the source of the illness to be a novel strain of Coronavirus, which was later designated as SARS-CoV-2. After an exponential increase in the number of infections, on January 23, 2020, the Chinese government ordered quarantine for the Wuhan city, and on January 28, 2020, over 4600 positive cases of the novel Coronavirus were reported and confirmed in several countries [1]. The COVID-19 disease had begun to reveal its lethality, claiming the lives of 106 victims. In the entire month of February, the virus began to exhibit significant expansion worldwide, leaving the governments no option other than adopting strict shutdown measures to contain the spread of the virus and flatten the curve of infection [2-6]. Soon, forced quarantines, curfews, and travel restrictions were applied throughout the world, resulting in sudden alterations in the psychological state of individuals at the interpersonal level and social discontent and critical economic instability at the global level. Indeed, the effects of the restrictions imposed by the national governments pushed the global economy into the worst recession since the Second World War. Initially, it was the supply shock that concerned the Chinese market (along with conspicuously significant consequences on the international market as well), although the rapid spread of the virus later caused a dramatic decline in demand as well, which deeply disrupted the consumption patterns and investments in every region in the world [711].

\subsection{Risk Factors in Society}

Relying upon a theoretical background, the authors considered it worth discussing the different sources of the transmission dynamics of the COVID-19 pandemic and the risk factors in the society driven by the interaction between air pollution and the meteorological factors, including the wind speed, that influence the air transport. The rapid and uncontrollable spread of the COVID-19 virus was indeed facilitated by the environmental disorders of the various populations worldwide as well as the different pollution intensities. Research has demonstrated the role of pollution in promoting the diffusion of the epidemic. In general, the viral infectivity via airborne pollution is influenced by particle composition, bacterial adaptive mechanisms, and meteorological conditions [12-18]. Coccia reported the involvement of two categories of causes that determined the incidence: the general factors and the more specific factors [19]. The first category is representative of each location and mostly dependent on the biological identity of the virus, such as its incubation time, viral load, etc. The specific factors, on the other hand, concern the local environmental context (such as the air 
pollution levels, meteorological conditions, etc.) as well as the socio-economic organization (population density and typology, healthcare infrastructures) and the emergency state management (specialized human resources, equipment, and funding provision). The current statistical data reported by studies [20-24] reveal that the highest rates of infected individuals and deaths associated with COVID-19 occurred in the cities with greater atmospheric stability, such as low wind speeds, colder temperature, and often high levels of air pollution, including exceeded safe levels of ozone or particulate matter [25-27]. Inverse changes in the AOD (aerosol optical depth) and $A E$ (Angstrom exponent) parameters during the lockdown restrictions reflected the decrease in the total aerosols in the air and the influence of the growth of fine-mode particles [28]. The econometric analyses based on the D2C (Casual Direction from Dependency) algorithm were performed to assess the unidirectional causal relationship between pollution (in terms of $\mathrm{CO}_{2}$ emissions, $\mathrm{PM}_{2.5}$, and $\mathrm{NO}_{2}$ ) per capita gross domestic product (GDP) and the COVID-19 disease in India [29] and three major French cities (Paris, Lyon, and Marseille) [30, 31], and the results were consistent with the findings already reported by the other authors [32-35]. In this context, there is an urgent requirement for developing a global prevention strategy against the air pollution that would safeguard the environment and human health, i.e., the application of sustainable development practices integrated with the promotion of research and political cooperation between the nations of the world [36, 37]. The present paper provides a database of information describing the overall state of the pandemic that would assist, in the future, in predicting the risk of the contagiousness of COVID-19 or any other viruses. In this context, the index C, which varies between 1.0 (high transmission risk) and 0 (low transmission risk), could be representative of the various boundary conditions (environmental, demographic, meteorological, and health risk factors) that may or may not favor the expansion of the pandemic phenomena across different territorial communities [38]. The exponential growth in the number of infections and the consequent implementation of restrictive measures on movements on a micro scale (urban and extra-urban) as well as on a macro scale (international and continental) have impacted the economy of the transport sector, particularly that of the aviation industry. On one hand, the economic crisis continues to create problems even during the recovery times for the transport sector, on the other hand, several scientific studies, including certain well-known studies and findings, have demonstrated a dramatic decline in the pollution levels following the lockdown measures. Therefore, it would be of significance to adopt political strategies encouraging a new phase of industrial development, while ensuring alongside, greater attention to the environmental requirements. The COVID-19 pandemic being a critical phase of a generalized nature, also represents an opportunity to invest more in research, new production processes, and new forms of sustainable energy.

\section{Aspects of the Covid-19 Pandemic in Relation to Air Transport}

Air transport has, for years, been a strong pillar for commercial networks worldwide. Among the western nations, the United States of America has been drastically affected by the crisis, particularly concerning the airline industry. A study [39] examining the short-term impact of COVID-19 on the stock performance of 52 airlines reported that the initial announcements regarding the spread of the virus caused a decline in air travel even before the formalization of the restrictive measures. The authors raised awareness of the short-term development of policy attitudes with the aim of alleviating the impact of the pandemic on the aviation sector worldwide and encouraging 
investments in the sector. Resilience is defined as the ability to preserve a certain level of regular/nominal performance following a disruptive large-scale event. A study reported developing several analytical methodologies, including data on airport capacity, number of daily flights, proposed routes, the average number of passengers, among others [40]. In the current competitive times, air transport has emerged as one of the main means available for travel over long distances. However, it is required to guarantee the high standards necessary for the safe management of protected operations both in flight and on the ground. Observations on the field have revealed a prominent increase in the passenger boarding times following the individual health checks and the time dedicated to cabin disinfection. A redesign of the control procedures, therefore, becomes necessary [41]. Forecasts attest to a recovery of the air transport sector by 2022 for up to six years, although with a considerable influence of the geographical location, such as the Asia Pacific region expected to be the one that would have the fastest recovery, followed by North America and Europe [42]. The airlines with more fleets and a greater diversity of aircraft are certainly going to be the most flexible to this outbreak [43]. Airports are the real hubs for the economy of each nation in terms of the exchange of goods and culture occurring daily on the airports. A study was conducted on different pairs of airports to address their planning issues in relation to territorial economic development and countries such as Italy, Norway, and Cyprus were investigated [44, 45]. The objective of the study was to define a level of economic and financial equilibrium for the airports that coexist in the same territorial regions, to ensure a fair and balanced growth of the GDP (p.i.). The results of the GIS (Geographic Information System) analysis performed led to a comprehensive SWOT (Strengths, Weaknesses, Opportunities, and Threats) analysis to identify the assets and the weaknesses of the studied airports [46-49]. According to the EU27, in the first quarter of the year 2020 , the impact of the losses to the aviation industry would have negatively reduced the world GDP from $0.02 \%$ to $0.12 \%$, while at the end of 2020 , the loss could be $1.41 \%-1.67 \%$ or even $1.66 \%$ $1.98 \%$ [50]. These critical scenarios include both flight-tracking data and reduced or canceled bookings, along with the assumptions based on the experience of previous pandemics that affected the aviation industry. In this context, safety science is a key factor that could assist in establishing short-, medium-, and long-term policies aimed at reducing the spread of the virus, while minimizing the negative impacts of the pandemic in the economic and social contexts. In the context of the COVID-19 virus, science indeed plays a crucial role in contributing to the formulation of policies and decisions for short-, medium-, and long-term to deal with the socio-economic crisis in terms of both transportation and safety. In a study [51], assessing the relationship between the COVID-19 diffusion and the transport accessibility of a specific area, a multiple linear regression model was implemented to explain this correlation, including the total provincial positive cases of COVID-19 (according to the Italian Ministry of Health data [52]), as dependent variables, while the socioeconomic factors, (population density, percentage of the elderly residents, number of employees, and number of companies), territorial measurements (coastline length, square kilometers of the urban areas), environmental indices (pollutant emissions, particulate matter average concentrations), health care measures (number of COVID-19 tests/day), transportation variables (accessibility to road/rail vehicles, percentage of trips), were used as independent variables. The statistical results revealed the variable of rail transport with the highest weight in terms of the number of COVID-19 infections (approximately $40 \%$ by weight), followed by the variables of a purely socio-economic kind, i.e., population density (approximately $14 \%$ by weight), and territorial and polluting indices (geographical position and PM pollutant -greater than $2 \%$ and approximately $7 \%$ 
by weight, respectively). Air transport is, therefore, one of the most affected sectors in terms of the critical economic impact of the pandemic. The future of air transport is currently uncertain, and it is, therefore, imperative to formulate administrative policies to identify ways for the survival of the aviation industry during the recovery phase and beyond [53]. Close cooperation between transport planning and the legislative systems is necessary [54]. In a study [55], authors proposed a novel intervention policy planning approach, which they referred to as PASS, to deal with the COVID-19 crisis and the future pandemics. The approach included four major conceptual macro-categories of P (Prepare-Protect-Provide), A (Avoid-Regulate), S (Move-Share), and S (Substitute-Interrupt) to fill the current gaps in the definition of transport to safeguard the economy of the entire stakeholder chain and the public healthcare. Government policies are warranted to reorganize the economic plans for industries while ensuring resources and funds to reduce people inequalities rather than intensifying them $[56,57]$. The upward trend in the epidemiological curve has irreparably damaged the tourism industry worldwide and, along with it, air transport could be placed in the list of sectors that were the most affected by the pandemic [58]. The ECB (European Central Bank) has issued a sinister alarm, stating: "Decline in the activity of international airlines would be much wider and deeper following the COVID-19 pandemic, and would probably have more lasting consequences compared to 9/11 and SARS". According to a bulletin of the European banking institution, the impact of the Coronavirus on the air navigation sector did not bode well, and the chaos at the airports would last no less than three years [59]. The International Air Transport Association (IATA) has predicted complicated times for the airline industry [60]. Several critical scenarios for the advancing crisis were proposed at the beginning of the lockdown measures (March 2020): one more contained and another one more dramatic. The first one, i.e., the Limited Spread scenario, would imply a \$63 bn loss accounting for $11 \%$ of the revenue passenger kilometers (RPK) worldwide in 2020 . In the second one, i.e., the Extensive Spread scenario, the drop would be $19 \%$ with a loss of $\$ 113 \mathrm{bn}$. Months later, the airlines would struggle to cut unit costs sufficient enough to prevent cash burn from continuing throughout 2021, as predicted based on the current demand assumptions and in the absence of further government support [61]. As the IATA chief economist Brian Pearce stated, "Airlines are still going to be burning through cash and making significant losses next year", despite the industry's efforts to scale down for much lower levels of demand. Another report stated: "The collapse of flight capacity across regions is unprecedented in the aviation history." Following the terrorist attacks of September 2001, the lack of passengers caused a 15\% decline, and it required an average of three years for a full recovery of this loss in just the United States and Europe. With the outbreak of SARS in 2002-2003, the airline industry encountered a decline of approximately two-thirds in the passenger revenue, and an improvement was reported only a year later. However, the Coronavirus pandemic is expected to cause much deeper damage that would be extremely difficult to recover from, with certain irreversible consequences that would require a minimum of three years or more for a complete recovery. As of June 2020 , a $65 \%$ decline in flight capacity was recorded globally. In the United States and Japan, flight capacity decreased by $72 \%$ and $48 \%$, respectively. In China, the flight capacity decreased by 71\%, to a value 20\% lower than that in 2019. In Italy, Spain, France, and Germany, flight capacity declined by over $90 \%$ compared to the previous year [62]. In the month of July 2020, the restart tests were certified in the air transport sector, demonstrating a slight improvement compared to the previous month. According to the National Civil Aviation Authority (ENAC), the EU flights have resumed more significantly, while the non-EU flights are still quite limited due to the entry restrictions imposed by the respective non-EU countries. 
It is important to restore the passengers' confidence in the safety of air travel. According to the reports of ENAV (the body that manages civil air traffic in Italy), the data concerning air traffic grew steadily, particularly during the month of July 2020. The number of flights has doubled compared to the previous month. The movements recorded by the ENAV were a total of 33000 , with a daily average of 2200 flights and a maximum peak of 2521 flights on 10 July. Therefore, in the first half of July $2020,20 \%$ of the air traffic was resumed, and the decline was reduced to $66 \%$ compared to the previous year. The gradual resumption of flights in the "Bel paese" proved to be in line with the growth trend recorded in the rest of Europe as well, with a further improvement observed in August. According to the Italian "Cassa Depositi e Prestiti" Think Tank study, the air transport industry represents $2.4 \%$ of the world GDP, accounting for 1800 billion dollars. The entire supply chain employs nearly 29 million people, including direct, indirect, and induced employment. The world is, therefore, witnessing a sharp contraction in the aviation sector, and the financial situation at the end of the year" would be unsustainable. The debt of the companies would become 120 billion higher than the level at the end of 2019, accounting for a total of 550 billion dollars, equivalent to approximately $92 \%$ of the revenues expected next year". The IATA has ascertained certain considerations: the receipts would fall by $50 \%$ to 419 billion dollars, and a rise is expected in 2021 with 598 billion dollars. However, a critical situation has been announced for the coming year as well, and the most affected companies would be those of the Asia-Pacific region (-29 billion dollars), followed by those of North America (-23.1 billion dollars) and Europe (-21.5 billion). Unfortunately, the serious crisis that this sector has suffered has also caused repercussions at the employment level, and the companies have announced their intention to implement a clean cut of employees. In addition to this tragic consequence, closures of several hubs are planned. Easy Jet, for example, is going to close three bases in the United Kingdom, while the low-cost airline Ryanair plans to close certain bases in Europe until the total recovery of the sector [63]. "The aviation industry has never faced a situation like this," states the Eurocontrol general director, Eamonn Brennan, sadly, during an exchange of views with the European Parliament's Committee on Transport and Tourism (Tran). Indeed, the number of flights, which had significantly increased gradually during the summer, began to drop drastically once again at the beginning of autumn. The COVID-19 crisis has demonstrated to the entire array of investors, political governors, and the general public that natural disasters are capable of causing economic damage on an unprecedented scale.

\section{Discussion and Conclusions}

The lockdown period imposed due to the COVID-19 pandemic has undoubtedly lowered the levels of air pollutants in most of the cities across the world, and there has been a considerable decline in large-scale energy consumption, such as in the industrial plants, as well as in the transport flows. These scenarios have led to a few interesting observations regarding air quality management. In this context, the pandemic crisis offers an opportunity to focus on the possible global initiatives, such as the optimization of fuels, designing of environmentally sustainable means of transport, and re-adaptation of the current means of transport, among others [64]. The gradual shift toward electric or hybrid motorization in both private and public transport appears to be the right direction to be undertaken. The global phenomenon has caused a reorganization of daily activities and habits of the people worldwide. The new normal of remote work has certainly encouraged a reduction in work-related trips. Policy initiatives should balance these transformation processes with targeted 
strategies, learning a lesson from the pandemic experience and encouraging a new normal of the daily living activities and the concept of work [65-67]. Furthermore, the decrease in environmental pollution would only be temporary until the world returns to a regular pace. However, the pandemic has invited a necessary reflection on climate change and the emission of polluting gases, which is perhaps the only positive note related to this pandemic that has affected the entire world population. For instance, the province of Hubei, during the quarantine, witnessed a drastic decrease in the concentrations of nitrogen dioxide $\left(\mathrm{NO}_{2}\right)$ and atmospheric particulate matter of dimensions below $2.5 \mu \mathrm{m}$ ( $\mathrm{PM}_{2.5}$, suspended particulate matter) in its major Chinese cities. In New York, the air pollution levels dropped by almost $50 \%$ during the lockdown period, while the satellite images of Europe revealed that the $\mathrm{NO}_{2}$ emissions of the continent had fallen dramatically. Despite these decreases in the greenhouse gas emissions due to the restrictions imposed for containing COVID19 , only a minimal effect has been exerted on the collective concentrations of these gases accumulated for decades in the atmosphere. In order to achieve a radical change in the current environmental and climatic situation, a long-term change should occur, which would require the national economies to commit to adopting environmental protection policies. The recent Legambiente campaign "The caravan of glaciers" encourages "to implement ambitious political measures for the climate to achieve net emissions equal to zero by 2040, rather than 2050, in line with the Paris agreement, an issue which, unfortunately, appears to remain out of the current political discussion in our country". Unfortunately, nine out of ten people worldwide breathe polluted air, which results in the death of 4.2 million people worldwide every year, while 412,000 deaths are estimated across Europe, of which 374,000 recorded in the $28 \mathrm{EU}$ countries are because of exposure to $\mathrm{PM}_{2.5}$. In this context, it would be interesting to evaluate the negative impact of air pollution on the incidence and evolution of COVID-19 as well as the positive impact of the reduced pollution levels during the pandemic lockdown period. Among the "side benefits" of the lockdown, one could certainly place the reduction in the noise pollution and an improvement in the waste disposal process, particularly on the beaches, where all kinds of toxic wastes from flora and fauna often accumulate carelessly. The marine waters have assumed a clearer aspect, and the beaches have returned to their original aspect. However, if one considers the general atmospheric conditions, an increase in the toxic and sanitary wastes has been observed, including masks, gloves, and used or expired drugs, which should be disposed of separately and not along with the household waste. Therefore, once again, environmental protection has definitely been compromised by a different type of pollution $[68,69]$. The restrictions imposed by the government have weighed heavily on the aeronautical sector, particularly its civil wing. The concept of travel has been questioned with a broadcasted risk for the public. Air transport has undergone a general review of all its rules and regulations, which the airline companies must comply with. The international bodies, such as ICAO, ACI, CANSO, IATA, TIACA, WFP, and WHO, have cooperated in the development of specific aviation guidelines to ensure appropriate planning and action at all levels, in order to mitigate the effects of the pandemic $[70,71]$. The global pandemic might have thrown the aviation industry into crisis, a shutdown of international fleets had the worst effect, but it has revived the drive to significantly reduce the carbon dioxide $\mathrm{CO}_{2}$ emissions from commercial aircrafts. Moreover, the global recession has revitalized the drive to significantly reduce the $\mathrm{CO}_{2}$ emissions from commercial aircrafts due to the drastic reduction in the number of flights. In this critical scenario, the crisis has accelerated the long-term greening of air transport. The political-economic challenge would be to balance connectivity and offer competition in the aftermath of the end of the pandemic. The governments 
must prioritize the maintenance of the climatic and environmental targets attained in these crucial months of lockdown, while looking at the industrial future not with limitations but with incentives to reach high levels of eco-sustainability [72-76]. Short-term practical recommendations should encourage a rearrangement of funding and dialogue for long-term planning with different stakeholders and shareholders with constructive and stimulating strategies should be promoted [77]. The reorganization is required not only in the funding process but in the infrastructure as well. The airport hubs would have to increase the forms of passenger control, as well as increase the number of employees and services to prevent the slow down of the check-in and boarding times [78]. Standard operating procedures would also require redesigning to include the upcoming healthcare necessities [41]. With the objective of sustaining the declining capacities and revenues, the IATA is calling on the EU governments to provide relief to their airlines by building cost control plans and integrating innovations according to the demand for supporting their operations [79]. The achievement of the environmental objectives during the lockdown period encourages the nations to maintain this trend in the future as well. The companies have increased their initiatives for the renewal of old fleets in favor of greener vehicles. Studies have highlighted that the effects of the COVID-19 pandemic on air transport could be considered a fresh opportunity with better avenues. A novel perspective for the foundation of a new air transport market that would also consider the associated environmental impacts must be properly scheduled, and most importantly, financed by state incentives [80]. Government strategies are placing the development of zero-emission aircrafts at the core of the industry's support packages, with the estimated release times of up to ten years. However, the aircraft industry has already demonstrated significant progress in reducing emissions over the past few decades. Indeed, the most recent in-service aircrafts today are over approximately $80 \%$ more fuel-efficient than the early 1960 s jets, owing to considerable investments in related research and development. The global commitment would be to reduce the greenhouse gas emissions to half of the 2005 baseline levels by 2050. The new-generation aircrafts, such as Airbus A320neo, A350, and Boeing B787 Dreamliner, are already replacing the fleets of older aircrafts, such as Boeing 747 jumbo jet and Airbus A380. The French government has announced a $€ 15$ billion support plan for the aerospace industry, which includes $€ 1.5$ billion for a three-year research on the development of greener aircrafts. This evolutionary process toward a more sustainable aviation industry is a welcome step, as the global industry produces approximately $2 \%$ of the human-induced emissions of $\mathrm{CO}_{2}$. Aviation is responsible for approximately $12 \%$ of the $\mathrm{CO}_{2}$ emissions from all the transport sources, compared to the $74 \%$ produced from road transport. The active participation of the government entities and banks is, therefore, strongly required. First of all, among the investment risk mitigation measures, it would be good to indicate an improvement in business and relations with the governments and potential partners. Implementing measures to overcome the crisis must, on one hand, balance the economic requirements of the realities that work around aeronautics, and on the other hand, ensure the environmental priorities concerning the issues of pollution and sustainability [72]. The research would have to refer to both these requirements. An assessment study [81] identified the performance aspects of the industrial supply chain following the pandemic outbreak and reported lead-time and epidemic propagation speed as the parameters that could be used by the decision-makers to predict the risk levels of the operative and long-term recovery policies. Another study [82] provided the conceptual and methodological contributions to crisis management and purchase intent research along with practical insights for the airline industry. Future research in this regard should include quantitative analysis to investigate the associations 
among the business improvements as well as the associations between relationships (companies, governments, and partners) and the consequences on corporate stock indices to promote rapid economic-financial recovery and volatility of the equity indices as well. The limitations to be considered in such a process of significant change are mostly associated with the inertia of different government realities and economic macrostructures. While the pandemic was able to disturb the global equilibrium in just a few months, it is not certain that all the countries of the world would adapt at the same pace. Currently, strong inequalities exist among the world economies, and several countries would require a longer time to recover according to their level of productivity and financial attractiveness. The gradually developing countries may have suffered less from the industrial crisis, precisely because they never participated actively in the world economic balances. Nonetheless, even these countries would require financial subsidies and infrastructures aimed at the substantial improvement in health and social sectors to prevent further exacerbating the differences with the other nations.

\section{Acknowledgments}

The authors are very grateful to all four reviewers for their constructive support in finalizing the present article.

\section{Author Contributions}

Both the authors have equally contributed to this work.

\section{Competing Interests}

The authors have declared that no competing interests exist.

\section{References}

1. Worldometer. COVID-19 Coronavirus Pandemic. 2020.

2. Qiu Y, Chen X, Shi W. Impacts of social and economic factors on the transmission of Coronavirus Disease 2019 (COVID-19) in China. J Popul Econ. 2020; 33: 1127-1172.

3. Wang C, Liu L, Hao X, Guo H, Wang Q, Huang J, et al. Evolving epidemiology and impact of nonpharmaceutical interventions on the outbreak of Coronavirus Disease 2019 in Wuhan, China. medRxiv. 2020; 323: 1915-1923.

4. Slater A. The economic cost of Coronavirus lockdowns. Oxf Econ. 2020; 44: 17-19.

5. Chin KL, Ofori-Asenso R, Jordan KA, Jones D, Liew D. Early signs that COVID-19 is being contained in Australia. J Infect. 2020; 81: 318-356.

6. Shaked I, Orelowitz B. The airline industry and COVID-19: Saving for a rainy day. Am Bankruptcy Inst J. 2020; 39: 36-37, 57-58.

7. Ibn-Mohammed T, Mustapha KB, Godsell J, Adamu Z, Babatunde KA, Akintade DD, et al. A critical analysis of the impacts of COVID-19 on the global economy and ecosystems and opportunities for circular economy strategies. Resour Conserv Recycl. 2021; 164: 105169.

8. Oravský $R$, Tóth $P$, Bánociová $A$. The ability of selected European countries to face the impending economic crisis caused by COVID-19 in the context of the global economic crisis of 2008. J Risk Financ Manag. 2020; 13: 179. 
9. Hassan MM, Kalam MA, Shano S, Nayem MR, Rahman MK, Khan SA, et al. Assessment of epidemiological determinants of COVID-19 pandemic related to social and economic factors globally. J Risk Financ Manag. 2020; 13: 194.

10. Thorbecke W. The Impact of the COVID-19 pandemic on the U.S. economy: Evidence from the stock market. J Risk Financ Manag. 2020; 13: 233.

11. Thorbecke W. How the Coronavirus crisis affected Japanese industries: Evidence from the stock market [Internet]. Tokyo: Research Institute of Economy, Trade and Industry (RIETI); Updated June 2020. Available from: https://www.rieti.go.jp/en/publications/nts/20e061.html.

12. Jones AM, Harrison RM. The effects of meteorological factors on atmospheric bio aerosol concentrations-a review. Sci Total Environ. 2004; 326: 151-180.

13. Zhang $\mathrm{T}$, Li $\mathrm{X}$, Wang $\mathrm{M}$, Chen $\mathrm{H}$, Yao M. Microbial aerosol chemistry characteristics in highly polluted air. Sci China Chem. 2019; 62: 1051-1063.

14. Zhai $Y$, Li X, Wang T, Wang B, Li C, Zeng G. A review on airborne microorganisms in particulate matters: Composition, characteristics and influence factors. Environ Int. 2018; 113: 74-90.

15. Wei M, Liu H, Chen J, Xu C, Li J, Xu P, Sun Z. Effects of aerosol pollution on PM2.5-associated bacteria in typical inland and coastal cities of northern China during the winter heating season. Environ Pollut. 2020; 262: 114188.

16. Kampa M, Castanas E. Human health effects of air pollution. Environ Pollut. 2008; 151: 362-367.

17. Hoek G, Krishnan RM, Beelen R, Peter A, Ostro B, Brunekreef B, et al. Long-term air pollution exposure and cardiorespiratory mortality: A review. Environ Health. 2013; 12: 43.

18. Langrish JP, Mills NL. Air pollution and mortality in Europe. Lancet. 2014; 383: 758-760.

19. Coccia M. Factors determining the diffusion of COVID-19 and suggested strategy to prevent future accelerated viral infectivity similar to COVID. Sci Total Environ. 2020; 729: 138474.

20. Barthelmie RJ. The effects of atmospheric stability on coastal wind climates. Meteorol Appl. 1999; 6: 39-47.

21. Snow DA. Plant Engineer's Reference Book. 2nd et. Oxford: Butterworth-Heinemann; 2002.

22. Pamuk O, Akyol A, Aslan Z. The role of atmospheric instability and importance of wind shear exponent on wind and solar energy potential. EGU General Assembly Conference; 2013 April 712; Vienna, Austria. Munich: European Geosciences Union GmbH.

23. Zhong J, Zhang $X$, Dong $Y$, Wang $Y$, Wang J, Zhang $Y$, et al. Feedback effects of boundary-layer meteorological factors on explosive growth of $\mathrm{PM}_{2.5}$ during winter heavy pollution episodes in Beijing from 2013 to 2016. Atmos Chem Phys. 2018; 18: 247-258.

24. Amster EJ. History's crystal ball: What the past can tell us about COVID-19 and our future [Internet]. Updated 28 June 2020. Available from: https://wp.nyu.edu/covid19histories/2020/07/10/historys-crystal-ball-what-the-past-can-tellus-about-covid-19-and-our-future/.

25. Coccia M. The effects of atmospheric stability with low wind speed and of air pollution on the accelerated transmission dynamics of COVID-19. Int J Environ Stud. 2021; 78: 1-27.

26. Coccia M. How do low wind speeds and high levels of air pollution support the spread of COVID19? Atmos Pollut Res. 2020; 12: 437-445.

27. Sarkodie SA, Owusu PA. Impact of meteorological factors on COVID-19 pandemic: Evidence from top 20 countries with confirmed cases. Environ Res. 2020; 191: 110101. 
28. Shen L, Zhao T, Wang H, Liu J, Bai Y, Kong S, et al. Importance of meteorology in air pollution events during the city lockdown for COVID-19 in Hubei Province, Central China. Sci Total Environ. 2021; 754: 142227.

29. Mele M, Magazzino C. Pollution, economic growth, and COVID-19 deaths in India: A machine learning evidence. Environ Sci Pollut Res. 2021; 28: 2669-2677.

30. Magazzino C, Mele M, Schneider N. The relationship between air pollution and COVID-19related deaths: An application to three French cities. Appl energy. 2020; 279: 115835.

31. Magazzino C, Mele M, Schneider N, Strezov V. NO 2 levels as a contributing factor to COVID-19 deaths: The first empirical estimate of threshold values. Environ Res. 2021; 194: 110663.

32. Bianchi F, Cibella F. Covid-19: A puzzle with many missing pieces. BMJ. 2020; 368: m627.

33. Cheng VC, Wong SC, Chen JH, Yip CC, Chuang VW, Tsang OT, et al. Escalating infection control response to the rapidly evolving epidemiology of the Coronavirus Disease 2019 (COVID-19) due to SARS-CoV-2 in Hong Kong. Infect Control Hosp Epidemiol. 2020; 41: 493-498.

34. Conticini E, Frediani B, Caro D. Can atmospheric pollution be considered a co-factor in extremely high level of SARS-CoV-2 lethality in Northern Italy? Environ Pollut. 2020; 261: 114465.

35. Schwartz KL, Murti M, Finkelstein M, Leis JA, Fitzgerald-Husek A, Bourns L, et al. Lack of COVID19 transmission on an international flight. CMAJ. 2020; 192: E410.

36. United Nations Framework Convention on Climate Change. Paris Climate Change Agreement 2016 [Internet]. Available from: https://unfccc.int/process-and-meetings/the-parisagreement/the-paris-agreement.

37. Manisalidis I, Stavropoulou E, Stavropoulos A, Bezirtzoglou E. Environmental and health impacts of air pollution: A review. Front Public Health. 2020; 8: 14.

38. Coccia, M. An index to quantify environmental risk of exposure to future epidemics of the COVID-19 and similar viral agents: Theory and practice. Environ Res. 2020; 191: 110155.

39. Maneenopa S, Kotcharin S. The impacts of COVID-19 on the global airline industry: An event study approach. J Air Transp Manag. 2020; 89: 101920.

40. Jakšić Z, Janić M. Modeling resilience of the ATC (Air Traffic Control) sectors. J Air Transp Manag. 2020; 89: 101891.

41. Schultz M, Evler J, Asadi E, Preis H, Fricke H, Wu C-L. Future aircraft turnaround operations considering post-pandemic requirements. J Air Transp Manag. 2020; 89: 101886.

42. Gudmundsson SV, Cattaneo M, Redondi R. Forecasting temporal world recovery in air transport markets in the presence of large economic shocks: The case of COVID-19. J Air Transp Manag. 2021; 91: 102007.

43. Pereira DD, Soares de Mello JC. Efficiency evaluation of Brazilian airlines operations considering the Covid-19 outbreak. J Air Transp Manag. 2021; 91: 101976.

44. Massaro A, Rossetti S. Comparing proximity for couples of close airports. Case studies on cityairports in the pre COVID-19. J Air Transp Manag. 2021; 91: 101977.

45. Calderon $E$, Ventura $P$, Massaro A. Air transport implications in tourist destinations. The Trapani Airport in Western Sicily. TeMA. 2019; 12: 331-350.

46. Cook GN, Billig BG. Airline operations and management - A management textbook. New York: Routledge; 2017.

47. Graham A. Managing airports: An international perspective. London: Routledge; 2014.

48. Kazdaa A, Hromádka M, Mrekajb B. Small regional airports operation: Unnecessary burdens or key to regional development. Transp Res Procedia. 2017; 28: 59-68. 
49. Young SB, Wells AT. Airport planning \& management. New York: McGraw-Hill Professional; 2011.

50. lacus SM, Natale F, Santamaria C, Spyratos S, Vespe M. Estimating and projecting air passenger traffic during the COVID-19 coronavirus outbreak and its socio-economic impact. Saf Sci. 2020; 129: 104791.

51. Cartenì A, Di Francesco L, Martino M. The role of transport accessibility within the spread of the Coronavirus pandemic in Italy. Saf Sci. 2021; 133: 104999.

52. Italian Ministry of Health, 2020. Daily reports on COVID-19 positive cases [Internet]. Available from: http://www.salute.gov.it/portale/home.html.

53. Amditis A. Opinion: Mobility in the aftermath of the covid-19 pandemic [Internet]. 2020. Available from: https://www.traffictechnologytoday.com/opinion/.

54. Deutsch C. Origins of metropolitan transportation planning and the urban stakes of interstate highway funding, 1956-1962. Transp Res Rec. 2014; 2453: 94-99.

55. Zhang J. Transport policymaking that accounts for COVID-19 and future public health threats: A PASS approach. Transp Policy. 2020; 99: 405-418.

56. Ahmed F, Ahmed N, Pissarides C, Stiglitz J. Why inequality could spread COVID-19. Lancet Public Health. 2020; 5: e240.

57. Vos R, Martin W, Laborde D. How much will poverty increase because of COVID-19 [Internet]? Washington: International Food Policy Research Institute; Updated 20 March 2020. Available from: https://www.ifpri.org/blog/how-much-will-global-poverty-increase-because-covid-19.

58. Liu J, Qiao P, Ding J, Hankinson L, Harriman EH, Schiller EM, et al. Will the aviation industry have a bright future after the COVID-19 outbreak? Evidence from Chinese airport shipping sector. J Risk Financ Manag. 2020; 13: 276.

59. Donthu N, Gustafsson A. Effects of COVID-19 on business and research. J Bus Res. 2020; 117: 284-289.

60. Pearce B. IATA economic reports: COVID-19 updated impact assessment of the novel Coronavirus [Internet]. Updated 5 March 2020. Available from: https://www.iata.org/en/iatarepository/publications/economic-reports/.

61. Goodell JW. COVID-19 and finance: Agendas for future research. Financ Res Lett. 2020; 35: 101512.

62. Web magazine on EU. Available from: www.eunews.it.

63. AGI - Italian Journalist Agency webpage. Availble from: www.agi.it.

64. UN Environment Programme, BloombergNEF. Global trends in renewable energy investment 2019. Available from: https://wedocs.unep.org/bitstream/.

65. Le Quéré $C$, Jackson RB, Jones MW, Smith AJ, Abernethy $S$, Andrew RM, et al. Temporary reduction in daily global $\mathrm{CO}_{2}$ emissions during the COVID-19 forced confinement. Nat Clim Chang. 2020; 10: 647-653.

66. Global Energy Review 2020: The impacts of the Covid-19 crisis on global energy demand and $\mathrm{CO}_{2}$ emissions [Internet]. Paris: International Energy Agency; Updated April 2020. Available from: https://www.iea.org/reports/global-energy-review-2020.

67. Energy consumption under social distancing measures [Internet]. London: Octopus Energy; Updated 28 April 2020. Availabe from: https://tech.octopus.energy/data-discourse/2020social-distancing/index.html.

68. BBC news website. Availble from: www.bbc.com. 
69. Scientific web journal. Available from: www.rivistamicron.it.

70. ICAO (International Civil Aviation Organization) security and facilitation official page. Availabe from: https://www.icao.int/Security/COVID-19/.

71. Macilree J, Duval DT. Aeropolitics in a post-COVID-19 world. J Air Transp Manag. 2020; 88: 101864.

72. Abate M, Panayotis C, Alloysius JP. Government support to airlines in the aftermath of the COVID-19 pandemic. J Air Transp Manag. 2020; 89: 101931.

73. Sung J, Monschauer Y. Changes in transport behaviour during the Covid-19 crisis [Internet]. Paris: International Energy Agency; Updated 27 May 2020. Available from: https://www.iea.org/articles/changes-in-transport-behaviour-during-the-covid-19-crisis.

74. International Transport Forum. Restoring air connectivity under policies to mitigate climate change, COVID-19 transport brief [Internet]. Paris: International Transport Forum; Updated 20 May 2020. Available from: https://www.itf-oecd.org/sites/default/files/air-connectivity-covid19.pdf.

75. International Transport Forum. Government support measures for domestic air connectivity, case-specific policy analysis reports [Internet]. Paris: International Transport Forum; Updated 10 December 2018. Available from: https://www.itf-oecd.org/government-support-measuresdomestic-air-connectivity.

76. OECD. Job retention schemes during the COVID-19 lockdown and beyond, OECD Policy Responses to Coronavirus (COVID-19) [Internet]. Château de la Muette: The Organisation for Economic Co-operation and Development; Updated 12 October 2020. Available from: https://www.oecd.org/coronavirus/policy-responses/job-retention-schemes-during-thecovid-19-lockdown-and-beyond-0853ba1d/.

77. Linden E. Pandemics and environmental shocks: What aviation managers should learn from COVID-19 for long-term planning. J Air Transp Manag. 2021; 90: 101944.

78. Tabares DA. An airport operations proposal for a pandemic-free air travel. J Air Transp Manag. 2021; 90: 101943.

79. Serrano F, Kazda A. The future of airport post COVID-19. J Air Transp Manag. 2020; 89: 101900.

80. Gössling S. Risks, resilience, and pathways to sustainable aviation: A COVID-19 perspective. J Air Transp Manag. 2020; 89: 101933.

81. Ivanov D. Predicting the impacts of epidemic outbreaks on global supply chains: A simulationbased analysis on the Coronavirus outbreak (COVID-19/SARS-CoV-2) case. Transport Res E-Log. 2020; 136, 101922.

82. Kao GH, Wang SW, Farquhar JD. Modeling airline crisis management capability: Brand attitude, brand credibility and intention. J Air Transp Manag. 2020; 89: 101894. 


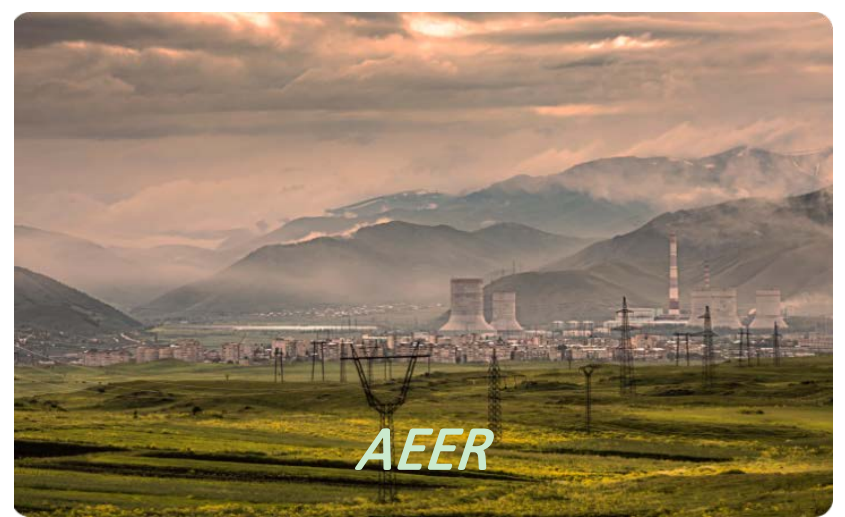

Enjoy $A E E R$ by:

1. Submitting a manuscript

2. Joining in volunteer reviewer bank

3. Joining Editorial Board

4. Guest editing a special issue

For more details, please visit:

http://www.lidsen.com/journals/aeer 